\title{
From pandemic to endemic: Examining transitions in blended learning in higher education
}

\author{
Shamini Thilarajah and Renuka Nasendran
}

Singapore National Institute of Education

\begin{abstract}
One year ago, the World Health Organisation (WHO) declared that COVID-19 was a pandemic. Twelve months on, we reflect on the educational change in Singapore and embrace the need to constantly re-imagine blended learning for living and learning with COVID-19. Using Dr Roger Greenaway's four F's of active reviewing - Facts, Feelings, Findings \& Future as the structure, this paper first presents the study of the transitions in blended learning of higher education pre-, during and post-pandemic lockdown. This review placed a spotlight on many gaps. Hence, this paper discusses pertinent issues following the review, particularly COVID-19 accelerated remote teaching, the 'Blended Learning@NIE' policy, and the policy-making process. This paper also reports the preliminary result of the policy implementation through the end-of-semester evaluation. The result is congruent with the feelings to develop digital fluency as teacher intuition for designing, developing and facilitating more meaningful blended learning experiences.
\end{abstract}

Keywords: Blended learning, higher education, digital fluency, teacher intuition, artificial intuition

\section{Introduction}

For much of the past year, Singapore was on track to bring the COVID-19 outbreak under control with the 'Circuit Breaker' phased approach, a nationwide partial lockdown. Ever since, blended learning has become the educational norm at the National Institute of Education (NIE), Singapore's only teacher education institution and an institute of Nanyang Technological University (NTU). The 'Blended Learning@NIE' policy was work underway from late 2018, and timely officiated in the second quarter of 2020. This policy is mainly a dynamic document that spells out the institute's definition of blended learning, the proposed model and a broad statement on goals.

Blended learning broadly relates to blending traditional face-to-face instruction and online learning instruction (Zacharis, 2015). Garrison and Vaughan (2008) go further to mention that blended learning is "the thoughtful fusion of face-to-face and online learning experiences" such that the strengths of each mode are meaningfully blended into an optimal learning experience.

'Blended Learning@NIE', built on similar ideologies, is a formal rotational flipped-blended learning approach that uses e-pedagogies to weave online with face-to-face learning experiences meaningfully with elements of learner control over Space, Time, Pace and Path where:

- Space: Learning is not restricted to physical places such as classrooms and homes and online places such as Learning Management Systems.

- Time: Learning is not restricted to formal learning hours.

- Pace: Learning is not restricted to the pace set by the teachers. Learners have the flexibility of setting a schedule to fit their needs.

- Path: Learning is not restricted to just one pathway for all learners.

In response to the COVID-19 pandemic, our faculty started leveraging technology more than in the past for remote teaching, meaning they responsively designed and developed instruction incrementally and often delivered it through their preferred technology to provide continuity during a loss of face-to-face lesson time. The increase in technology usage was evident from the data collected from NTULearn Blackboard Learning Management System (LMS) and NIE Google Workspace in academic years 2019 and 2020. In contrast to 2019's 82.66\%, 2020's 91.52\% usage indicated COVID-19 accelerated adoption. Platforms apart from NTULearn Blackboard and NIE Google Workspace were not considered. From the $91.52 \%$, a basic instructional analysis to investigate the course design and 'learner-centredness' on the courses utilised only the NTULearn 
Blackboard revealed that most of the courses used the LMS as a space to host asynchronous online lesson content and readings. Tools such as Blackboard Collaborate and Zoom were widely used for synchronous online teaching. While the degree of 'learner-centredness' is unclear based on the data collected, it is likely to be low due to the rapid scale-up to synchronous online learning. Hence, the transition of these courses to effective blended learning could potentially be challenging.

Post 'Circuit Breaker', face-to-face lessons resumed. In addition to the challenge of transiting from remote teaching to NIE's (rotational flipped) blended learning, some of our faculty felt compelled to re-design, redevelop and find new ways to facilitate Blend-Flexible (BlendFlex) courses for students overseas facing restrictions to travel, impeding their learning back on campus. BlendFlex, commonly known as Hybrid-Flex (HyFlex), is an instructional approach that allows students to choose in-person instruction or online instruction in real-time from a remote location (Beatty, 2014). Thanks to advances in global connectivity and video conferencing solutions, NIE immediately swung into action by integrating the social and technical affordances of Zoom software and Swivl ${ }^{\mathrm{TM}}$, a robotic mount for smart devices that tracks faculty while the included markers capture classroom audio and video as an effective way to connect in real-time with remote students of the BlendFlex courses.

By the last quarter of 2020, in just a matter of months, the plan has changed. 'Blended Learning@NIE' needed to evolve to accommodate BlendFlex and more.

\section{Facts}

Pre-pandemic, blended learning was not a formal instructional approach. There was no policy to govern this, i.e., there was no formal definition and guidelines to what constituted a blended course. Faculty practised blended learning in their courses based on their readiness and ability to design and implement suitable learning activities and tools for an online lesson.

\section{Blended Learning@NIE Policy}

The 'Blended Learning@NIE' policy was officiated in November 2020. The policy aimed for NIE to achieve $100 \%$ of its courses conducted as a blended course based on a staged approach where $90 \%$ of the courses to be offered as blended in the January 2021 semester and 100\% of the courses in the August 2021 semester.

To achieve these goals, capability development initiatives, a multi-prong approach to grow and develop faculty's blended learning knowledge and skills to ensure they are effective in their roles was promoted through Learning, Networking and Practising. The following were the initiatives implemented:

Learning: Providing professional learning opportunities for teachers

- "NIE Goes Online!" is a self-learning online course.

- "From Remote Teaching to Facilitating Online Lesson" is a workshop on blended learning foundation skills and best practices delivered by fellow faculty members.

- "Power-up in 60 " is a series of 60-min interactive, hands-on sessions on the use of NIE's blended learning tools and resources.

Networking: Enabling learning through social interactions among academics and practitioners

- "LearningXChange" is an online learning series on the works of educators, researchers, practitioners, gurus and industry partners worldwide.

- "Faculty Social Hour" is a dialogical platform for NIE faculty to communicate their needs in an informal, safe space such as a coffee talk.

- "Innovation in Teaching and Learning" is a biennial seminar on pedagogical innovations and provides opportunities for participants to collaborate and cross-pollinate ideas, as well as share best practices across the teaching community.

Practising: Facilitating innovative teaching and learning practices with digital tools

- "Blended Learning Innovation Space" (BLIS) is a microsite on NIE's private network that hosts official information on 'Blended Learning@NIE' and the Blended Learning Toolkit (refer to Figure 2) to scaffold the process of designing, developing and evaluating the quality of a blended course in NTULearn.

- "Swivl-with-Zoom" is a BlendFlex solution for faculty to seamlessly facilitate both the physical and online learning spaces in real-time. 
The conversations from the Learning and Practising initiatives, that directly contribute to the goals of the policy, provided valuable insights. While some faculty appreciated the suggestions offered on online teaching strategies and the templates, a number also critiqued the technical limitations of the Blended Learning Toolkit and the expectation gaps derived from the initiatives' outcomes and their perception of their competencies in designing blended courses.

Comments from faculty also suggest that the one-size-fits-all initiatives that aim to equip faculty with the fundamentals of blended learning require more work to understand faculty's self-efficacy, needs, readiness, and preferred learning method.

The following section presents the gaps further identified by the team when they gathered to discuss and process their feelings about the initiatives they have led.

\section{Feelings}

While faculty actively participated and expressed their gratitude for the Learning, Networking and Practising initiatives created with their blended course design needs in mind, our observations and their reactions left us feeling concerned about achieving the intended outcomes of the 'Blended Learning@NIE' policy. Our attempt to process our feelings objectively revealed:

- Faculty's self-perception of their blended learning competencies

As facilitators, we faced distinct and nuanced concerns raised by some faculty who were already familiar with pedagogical approaches, learning strategies, lesson sequencing approaches, and NTULearn Blackboard's use to develop their courses. Some mentioned they were familiar with the content covered.

- Faculty's perception of the use of technology in blended learning In our formal and informal conversations with faculty, we realised there were varying misperceptions amongst the faculty across the 10 academic groups in what constitutes blended learning vs technologyenhanced learning in the classroom that was often regarded as blended learning.

- Our perception of faculty's readiness to implement blended learning

The ‘Blended Learning@NIE' policy implementation was not timely for faculty to relook into the design and development of their courses. The policy was launched in November 2020, but the workshops, tools and resources to support the implementation were only available at the beginning of the January 2021 semester.

- Faculty's feedback on the lack of integration for various blended learning resources While faculty appreciated the provision of tools and initiatives to support them in their blended course design, we felt that they were disappointed by the lack of seamlessness in the digital solutions provided.

These gaps shed light on the reality of the situation and the need for our continual efforts to develop our faculty's self-efficacy, readiness and competencies to achieve the goals of the policy. Heinonen et al. (2019) found that university teachers regarded themselves as developers of technology-enhanced learning in higher education, as being active developers, adaptive developers, cautious developers and reluctant developers. These four divergent belief groups identified in their work provide a fresh perspective on designing customised initiatives to suit the different 'developers' within our faculty.

\section{Findings}

Regardless of the gaps and challenges encountered in the implementation journey, the NTULearn Blackboard blended course data provides an early indication of NIE's ability to offer quality blended courses with or without the initiatives to support the re-design of courses to a blended approach. An end-of-semester evaluation was conducted using Stufflebeam (1983)'s Context-Input- Process-Product (CIPP) evaluation model that systematically examines the current status of blended learning courses in NIE and how well the initiatives have achieved the intended goals.

A preliminary study was conducted on 339 NTULearn Blackboard (Product) courses offered in the January 2021 semester. Content analysis (Elo \& Kyngäs, 2008) of the course design was carried out following gathering course design data, opening coding, categorisation, organisation, and abstraction to report the face-to-face and 
online learning percentage and any emerging patterns.

Out of the 339 courses analysed, some courses fulfilled the blended learning criterion of $30 \%-60 \%$ of course duration to offer online instruction. It was encouraging to know that there were courses that surpassed the criteria. However, the timeliness of the policy implementation could have led to better outcomes as, based on past experiences, on average, a novice requires a minimum of 4.5 months to convert a full 13 -week face-to-face course to a blended approach. In our context, faculty had at most 2 months and that too was during the year-end holiday. Hence, undeterred by the untimely implementation of the policy, the data affirmed we have amongst us a divergent range of faculty from 'active and adaptive developers' who are highly ready for educational change and have an open mind towards educational technology (Heinonen et al. 2019).

The study also examined the extent of learner-centredness in the blended courses regarding Space, Pace, Time and Path of learning. The element with the highest autonomy of learning was Space. However, the element which was inadequate in most blended courses was Path. The lack of learner-centredness signals the need for initiatives to emphasise designing learner-centred blended courses.

With the positive correlations between our feelings and findings, it is imperative to calibrate our approach in developing the required capabilities for 'Blended Learning@NIE'.

\section{Conclusion and Future Work}

Broadly translated, our findings and feelings of this preliminary study confirm three things. One, given the inadequacies of our single data collection approach, validating the quantitative study using multiple sources and qualitative methods such as self-reporting surveys and focus group discussions is critical for a conclusive finding. Two, given the varying levels of competencies amongst the faculty (e.g., active, adaptive developers), it is pertinent to assess their different needs and readiness to design more effective capability development initiatives. Three, there is a need for a progressive blended learning policy to expect, welcome, and adapt to change and embark on a new agile policy-making approach, where we constantly seek feedback on policy performance and not wait for end-of-semester evaluations. Our preliminary study adds to the growing corpus of research in COVID-19 accelerated blended learning policy and the readiness of faculty in higher education.

In many ways, collegial support motivates and helps build a culture that helps people work together with purpose. In our future work, a Blended Learning Community under the Networking initiatives will contribute to creating a blended learning culture of experimenting and adopting best and new practices. In its attempt to develop and reinforce knowledge, skills and innovation in blended learning, the Learning, \& Practising initiatives will go beyond hard skills, the technical knowledge and skills related to designing and developing blended courses targeted at faculty's varying levels of competencies. It could include developing faculty's Digital Fluency, a necessary soft skill; non-technical skills that allow faculty to integrate the hard skills they possess during work processes, which are pivotal for digital teaching.

Digital fluency, also termed higher-order thinking skills, is among the critical skills needed to survive in a digitally connected society (McQuiggan et al., 2015). Digital fluency embraces both knowing how to use digital technology and 'knowing' how to construct ideas of significance with digital technology (Wang et al., 2012). The terms "literacy", "fluency", and "competency" are used interchangeably in literature to describe one's ability to navigate the digital environment to find, evaluate and accept or reject information (Belshaw, 2012).

In blended learning, digital fluency plays a critical role in faculty 'knowing' what, why, when, how and how much to use digital tools creatively and effectively to achieve intended learning outcomes. It has not been established empirically how digital fluency is developed among faculty, a gap that needs to be addressed, as recommended by Tusiime et al. (2019). Nevertheless, we view digital fluency as paramount in teacher education institutions as digital fluency forms an integral part of preparing digital age teachers in the 'knowing' how to navigate the complexity of teaching practice in teaching with technology. In our case, it can aid in addressing faculty's self-efficacy, needs and readiness. Studies exploring how educators develop digital fluency and the related skills are limited (Heinonen et al., 2019; McKnight et al., 2016; Tusiime et al., 2019). Hence, our future research could examine the role of digital fluency in teacher professional development.

Another approach to soft skills would be to build on the faculty's intuition during the course design process. Intuition can be defined 'as direct knowing without conscious information processing' (Sinclair, 2011). Intuition is indispensable for educators because it allows them to 'generate ideas, alternatives or solutions' (Sadler-Smith, 2004) and usually involves 'decision-making, problem-solving and creativity' (Dane \& Pratt, 2009). Building 
on the premise of teacher intuition, our future work also involves creating an online agent powered by artificial intuition, the 4th generation of artificial intelligence. This agent will aid in developing faculty's digital fluency in making data-driven, intuitive, technology-enabled lesson design decisions.

\section{References}

Beatty, B. (2014). Hybrid courses with flexible participation: The HyFlex course design. In Practical applications and experiences in K-20 blended learning environments (pp. 153-177). IGI Global.

Belshaw, D. A. (2012). What is' digital literacy'?: a pragmatic investigation Durham University].

Dane, E., \& Pratt, M. G. (2009). Conceptualizing and measuring intuition: A review of recent trends. International review of industrial and organizational psychology, 24(1), 1-40.

Elo, S., \& Kyngäs, H. (2008). The qualitative content analysis process. Journal of advanced nursing, 62(1), 107-115.

Garrison, D. R., \& Vaughan, N. D. (2008). Blended learning in higher education: Framework, principles, and guidelines. John Wiley \& Sons.

Heinonen, K., Jääskelä, P., Häkkinen, P., Isomäki, H., \& Hämäläinen, R. (2019). University Teachers as Developers of Technology-Enhanced Teaching_Do Beliefs Matter? Journal of Research on Technology in Education, 51(2), 135-151.

McKnight, K., O'Malley, K., Ruzic, R., Horsley, M. K., Franey, J. J., \& Bassett, K. (2016). Teaching in a digital age: How educators use technology to improve student learning. Journal of Research on Technology in Education, 48(3), 194-211.

McQuiggan, S., McQuiggan, J., Sabourin, J., \& Kosturko, L. (2015). Mobile learning: A handbookfor developers, educators, and learners. John Wiley \& Sons.

Sadler-Smith, E. (2004). Cognitive style and the management of small and medium-sized enterprises. Organization Studies, 25(2), 155-181.

Sinclair, M. (2011). An integrated framework of intuition. Handbook of intuition research, 1, 3-16.

Stufflebeam, D. L. (1983). The CIPP model for program evaluation. In Evaluation models. pp. 117-141. Springer.

Tusiime, W., Johannesen, M., \& Gudmundsdottir, G. (2019). Developing teachers' digital competence: Approaches for art and design teacher educators in Uganda. International Journal of Education and Development using ICT, 15(1).

Wang, R., Wiesemes, R., \& Gibbons, C. (2012). Developing digital fluency through ubiquitous mobile devices: Findings from a small-scale study. Computers \& Education, 58(1), 570-578.

Zacharis, N. Z. (2015). A multivariate approach to predicting student outcomes in web-enabled blended learning courses. The Internet and Higher Education, 27, 44-53.

Thilarajah, S., \& Nasendran, R. (2021). From pandemic to endemic: Examining transitions in blended learning in higher education. In Gregory, S., Warburton, S., \& Schier, M. (Eds.), Back to the Future - ASCILITE '21.

Proceedings ASCILITE 2021 in Armidale (pp. 236-240). https://doi.org/10.14742/ascilite2021.0135

Note: All published papers are refereed, having undergone a double-blind peer-review process.

The author(s) assign a Creative Commons by attribution licence enabling others to distribute, remix, tweak, and build upon their work, even commercially, as long as credit is given to the author(s) for the original creation.

(C) Thilarajah, S., \& Nasendran, R. 2021 